\title{
MicroRNA-181b stimulates inflammation via the nuclear factor- $\kappa B$ signaling pathway in vitro
}

\author{
YAZHEN WANG, GENXIANG MAO, YUANDONG LV, QINGDONG HUANG and GUOFU WANG \\ Zhejiang Provincial Key Laboratory of Geriatrics and Geriatrics Institute of Zhejiang, \\ Zhejiang Hospital, Hangzhou, Zhejiang 310013, P.R. China
}

Received September 12, 2014; Accepted July 29, 2015

DOI: $10.3892 /$ etm.2015.2702

\begin{abstract}
Acute lung injury (ALI) is characterized by severe lung edema and an increase in the inflammatory reaction. Considerable evidence has indicated that microRNAs (miRNAs or miRs) are involved in various human diseases; however, the expression profile and function of miRNAs in ALI have been rarely reported. The present study used miRNA microarray and reverse transcription-quantitative polymerase chain reaction to demonstrate that miR-181b is the one of the most significantly upregulated miRNA after lipopolysaccharide (LPS) stimulation in human bronchial epithelial cells, BEAS-2B. To elaborate the role of miR-181b in ALI, an assay was performed to investigate the overexpression of miR-181b in BEAS-2B cells, and the expression of inflammatory factors was then analyzed. The overexpression of miR-181b resulted in the induction of an increment in interleukin (IL)- 6 levels. p65 was identified to be a primary component of $N F-\kappa B$, since it was upregulated in the miR-181b overexpression in the BEAS-2B cells, while pyrrolidine dithiocarbamate, a specific inhibitor of $\mathrm{NF}-\kappa \mathrm{B}$, was found to be able to abrogate the upregulation of the expression of $\mathrm{p} 65$. In conclusion, the findings of the present study suggested that miR-181b may be involved in the process of LPS-induced inflammation in BEAS-2B cells by activating the $\mathrm{NF}-\kappa \mathrm{B}$ signaling pathway, which implies that it may serve as a potential therapeutic target for ALI.
\end{abstract}

\section{Introduction}

Acute lung injury (ALI), with acute respiratory distress syndrome (ARDS) being its most severe manifestation, is a common disease with hazardous effects on human health.

Correspondence to: Mr. Guofu Wang or Mr. Qingdong Huang, Zhejiang Provincial Key Laboratory of Geriatrics and Geriatrics Institute of Zhejiang, Zhejiang Hospital, 12 Lingyin Road, Hangzhou, Zhejiang 310013, P.R. China

E-mail: 1090983005@qq.com

E-mail: drhqd@126.com

Key words: acute lung injury, microRNA-181b, interleukin-6, lipopolysaccharide, human bronchial epithelial cells
Despite the positive survival trends that have been reported in the past two decades in patients with ALI/ARDS, the mortality rate remains at $30-50 \%$, particularly among older patients who exhibit sepsis, which is the most common predisposing factor (1). ALI/ARDS is partly characterized by persistent, uncontrolled pulmonary inflammation, which occurs in response to a variety of insults, including pneumonia, sepsis and trauma (2). Epithelial cells and macrophages comprise the primary line of defense, upon exogenous insults in the lung. A cascade of events is triggered by the injured cells, including acute inflammatory response, recruitment of immune cells, including monocytes and macrophages, and release of the cytokines, interleukin (IL)- 6 and tumor necrosis factor- $\alpha$ (TNF- $\alpha$ ) (3). IL-6 and TNF- $\alpha$ are transcriptional activators that is crucial to the activation of several proinflammatory genes in human respiratory epithelial cells $(4,5)$. The $\mathrm{NF}-\kappa \mathrm{B}$ protein family consists of homodimeric or heterodimeric subunits of members of the Rel family, including p50 and p65. Functional $\mathrm{NF}-\kappa \mathrm{B}$ dimers always contain a p65 subunit and possess marked proinflammatory activity (6). Despite considerable research and an increased understanding of the pathophysiological processes involved in the pathogenesis of ALI $(2,3)$, the mechanism of the disease remains to be elucidated.

MicroRNA (miRNA or miR) molecules are small, single-stranded, non-coding RNAs that typically bind to the 3' untranslated region (3'UTR) of target mRNA sequences, which results in reduced protein expression, mainly by destabilizing target mRNAs and/or through the inhibition of translation $(7,8)$. MiRNAs have been found to play an important role in various biological processes (9). Previous studies have demonstrated that miRNAs are dynamically regulated in various human diseases, including cardiovascular diseases $(10,11)$ and tumorigenesis $(12,13)$. In addition, certain studies have indicated that miRNAs are extensively involved in inflammation (14-16). Changes in the expression levels of certain miRNAs may be involved in the regulation of the inflammatory process and tissue repair in ALI/ARDS (17). Cai et al revealed that the levels of miR-16 were reduced in lipopolysaccharide (LPS)-induced experimental ALI (18). In addition, miR-16 treatment reduced the expression levels of the TNF- $\alpha$ and IL- 6 proinflammatory cytokines following exposure of macrophages to LPS. Furthermore, Xie et al identified a decrease in the pulmonary miR-127 expression in alveolar macrophages exposed to LPS and in an animal 
model of noninfectious ALI (19). miR-127 treatment was also demonstrated to reduce the IL- $1 \beta$, TNF- $\alpha$ and IL- 6 production in macrophages that had been exposed to LPS, as well as to reduce the lesion degree in an experimental ALI model in vivo. Iliopoulos et al (20) reported that, in ER-Src cells, miR-181b targets CYLD directly, which results in an increased $N F-\kappa B$ activity and maintenance of the inflammatory feedback loop underlying the epigenetic switch that links inflammation to cancer. Therefore, the therapeutic targeting of these miRNAs may be used as a way to suppress the inflammatory response following ALI. However, the role of miRNAs in the mediation of ALI has only recently been examined (18-20), and requires further investigation.

The aim of the present study was to characterize the regulation of the miRNA expression using LPS challenge. Through an miRNA array-based screen, miR-181b was identified as a regulator of BEAS-2B human bronchial epithelial cells using LPS challenge. The study investigated the effect of LPS treatment on the expression of miR-181b, as well as the association of miR-181b with the expression levels of p65 and inflammation-associated cell factors, such as IL-6, which are closely associated with ALI ARDS. In addition, the role of miR-181b in ALI and its potential application as a diagnostic and prognostic marker of the disease were investigated (21).

\section{Materials and methods}

Reagents. Fetal calf serum was obtained from Gibco-BRL (Grand Island NY, USA). The following materials were obtained from Qiagen (Hilden, Germany): miScript miRNA Mimic syn-hsa-miR-181b; Pre-miR miRNA negative control; QuantiTect primer assays; miScript II RT kit; miScript SYBR Green PCR kit; and HiPerFect transfection reagent. Pyrrolidine dithiocarbamate (PDTC), a specific inhibitor of $N F-\kappa B$, was purchased from Sigma-Aldrich (St. Louis, MO, USA). The TNF- $\alpha$ and IL-6 ELISA kits were from MultiSciences Biotech Co., Ltd. (Hangzhou, China; cat. nos. 70-E-EK1061 and 70-E-EK1821, respectively). The NE-PER extraction reagent and BCA protein assay kit were from Pierce Chemical Co. (Rockford, IL, USA). Monoclonal rabbit anti-human p65 antibodies (cat. no. 1546-s) were obtained from Epitomics (Burlingame, CA, USA). Anti- $\beta$-actin monoclonal antibodies (cat. no. sc-8432) were obtained from Santa Cruz Biotechnology Inc. (Santa Cruz, CA, USA).

Cell culture. BEAS-2B cells were obtained from the Second Affiliated Hospital of Zhejiang University School of Medicine (Hangzhou, China) and cultured in RPMI 1640 supplemented with $10 \%$ fetal calf serum and penicillin-streptomycin (100X; Gino Biomedical Technology Co., Ltd., Hangzhou, China) in a humidified $\mathrm{CO}_{2}$ incubator at $37^{\circ} \mathrm{C}$. When the cells reached $>85 \%$ confluence, they were trypsinized (Gino Biomedical Technology Co., Ltd.) and subcultured. The cells were generally used between passages 20-30 to avoid the generation of variation.

miRNA extraction and microarray analysis. BEAS-2B cells were seeded into 6 -well plates at a density of $5 \times 10^{5}$ cells/well for a 24-h incubation prior to LPS treatment. Duplicate wells were used as the controls (medium only). The remaining wells were stimulated with $10 \mu \mathrm{g} / \mathrm{ml}$ LPS (the LPS concentration was determined according to the pre-test and references) (22) for $24 \mathrm{~h}$. Subsequently, the cells were harvested for various assays, including RNA extraction, small RNA separation, quality control, labeling, hybridization and scanning, which were performed by LC Sciences LLC (Houston, TX, USA) using a Chip01_H16_070802 miRNA array chip, based on Sanger miRBase release $16.0(23,24)$ (http://www.mirbase. org). Preliminary statistical analysis was also performed by LC Sciences LLC on raw data normalized using the locally-weighted regression method on the background-subtracted data. The microarray used for the experiments contained three probe replicates for each miRNA. A value of $\mathrm{P}<0.01$ between pixels was considered to indicate a statistically significant difference.

Reverse transcription-quantitative polymerase chain reaction $(R T-q P C R)$. Total RNA extraction and small RNA separation were performed using the miRNeasy Mini kit (cat. no. 217004; Qiagen). Cells and total RNA were treated as previously described. RT was performed with $200 \mathrm{ng}$ RNA using the miScript II RT kit for miRNA transcription. RT-qPCR was performed using the miScript SYBR Green PCR kit, according to the manufacturer's instruction. Amplification and data analysis were performed using the 7500 Real Time PCR system (Applied Biosystems Life Technologies, Foster City, CA, USA). PCR cycling conditions were as follows: Inital activation at $95^{\circ} \mathrm{C}$ for $15 \mathrm{~min}$, followed by 40 cycles of annealing at $94^{\circ} \mathrm{C}$ for $15 \mathrm{sec}$, annealing at $55^{\circ} \mathrm{C}$ for $30 \mathrm{sec}$ and extension at $70^{\circ} \mathrm{C}$ for $35 \mathrm{sec}$. QuantiTect primer assays were used for the determination of miR-181b, miR-23c, miR-26b and Rnu6B expression. Values were normalized to the level of Rnu6B expression (Qiagen).

PDTC treatment. BEAS-2B cells were seeded in 6-well plates ( $3 \times 10^{5}$ cells/well). After $24 \mathrm{~h}$, the cells were treated with 50 , 100 or $200 \mu \mathrm{M}$ PDTC for $1.5 \mathrm{~h}$.

Transfection. BEAS-2B cells, with or without PDTC treatment, were transfected with miScript miRNA Mimic syn-hsa-miR-181b at $10 \mathrm{nmol} / \mathrm{l}$ using HiPerFect transfection reagent. Negative control, LPS $(10 \mu \mathrm{g} / \mathrm{ml})$ were used as positive control for miR-181b overexpression. The extent of miR-181b overexpression was measured by RT-qPCR. The supernatants, as well as the adherent cells, were collected at $48 \mathrm{~h}$ post-transfection for further analysis.

ELISA. Following transfection, the supernatants were collected at various time points $(0,12,24$ and $48 \mathrm{~h})$ by centrifuged at $1000 \mathrm{x} \mathrm{g}$ for $10 \mathrm{~min}$ and then stored in $-80^{\circ} \mathrm{C}$. The expression levels of TNF- $\alpha$ and IL- 6 were measured using the aforementioned commercial kits, according to the manufacturers' instructions. All absorbance results were normalized according to the standard curves.

Western blotting. For nuclear protein extraction, cells were lysed in NE-PER extraction reagent according to the manufacturer's instructions. Protein concentrations were determined using a BCA protein assay kit. A total of $30 \mu \mathrm{g}$ protein was then loaded and electrophoresed on a $12 \%$ SDS-polyacrylamide gel, and transferred to the nitrocellulose membrane. The 
membranes were subsequently probed with anti-p65 (1:1,000 dilution) and anti- $\beta$-actin (1:1,000 dilution) monoclonal antibodies, respectively. The secondary antibody used for detection was linked with horseradish peroxidase. Next, an enhanced chemiluminescence method was used to detect the conjugated horseradish peroxidase (EMD Millipore, Billerica, MD, USA) and Image J (version 1.49) was used to analyze the immunoblots.

Statistical analysis. Differences between groups were compared using the Student's t-test for continuous variables. $\mathrm{P}<0.05$ was considered to indicate a statistically significant difference.

\section{Results}

Elevated levels of IL-6 in BEAS-2B cells following LPS stimulation. LPS pretreatment has been previously used to model inflammation in animal inhalation experiments (25). In addition, LPS is known to induce the expression of proinflammatory cytokines, such as IL-6, in BEAS-2B and A549 cells (22). In the present study, the expression of IL-6 was initially examined (Fig. 1). Compared with the negative control, IL-6 expression was significantly increased in cells treated with LPS at each time interval $(\mathrm{P}<0.01)$. Elevated levels of this cytokine have been detected in patients with ARDS and shown to be directly associated with the severity of lung inflammation and mortality (26). In the current study, TNF- $\alpha$ secretion was not detected in culture supernatants from the negative control and syn-hsa-miR-181b groups. The lowest TNF- $\alpha$ standards showed good reproducibility (3.8\% coefficient of variation), thus the limit of detection was $<2.048 \mathrm{pg} / \mathrm{ml}$.

Activation of miR-181b in response to LPS stimulation in $B E A S-2 B$ cells. Although there is a poor understanding of the underlying mechanisms of ALI, an enhanced inflammatory response is known to be involved in this process and, at least partly, contribute to the development of the disease $(2,3)$. Notably, miRNAs are emerging as new regulators of inflammatory and immune responses (14). In order to investigate the potential role of miRNAs in LPS-challenged BEAS-2B cells, the miRNA expression profile was analyzed. Cells were treated with or without $10 \mu \mathrm{g} / \mathrm{ml}$ LPS for $24 \mathrm{~h}$ and then the RNA extraction was submitted for an miRNA chip assay (miRHuman_16.0_070802 miRNA array). The profile analysis revealed that the expression of 41 miRNAs, particularly that of miR-181b, miR-23c and miR-26b, presented significant alterations in LPS-treated cells $(\mathrm{P}<0.01$; Table I). The array results were further verified using $\mathrm{qPCR}$, which revealed that the expression of miR-181b, miR-23c and miR-26b was a bona fide target of certain signaling pathways (Fig. 2). Of these potential candidates, the focus was laid on miR-181b, since it was one of the most clearly altered miRNAs and is known to be deregulated in inflammation, although its function remains unclear $(27,28)$. In addition, miR-181b has recently been identified as a key player in a positive feedback loop linking inflammation to an epigenetic switch that controls cellular transformation in human mammary epithelial MCF-10A cells (20). The results of the current assay showed that the

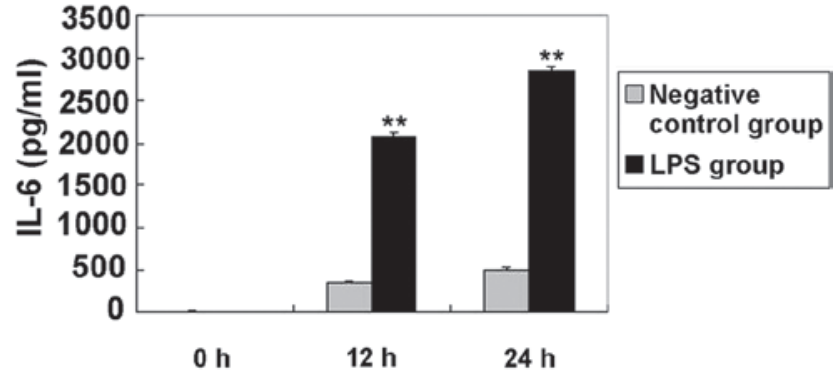

Figure 1. LPS-induced time-dependent release of IL-6 in BEAS-2B human bronchial epithelial cells. Cells were cultured with the negative control and LPS for 0,12 and $24 \mathrm{~h}$. Conditioned media were aspirated at each time interval and assayed for cytokine release using ELISA. The data are expressed as $\mathrm{pg} / \mathrm{ml}$ of the conditioned media, presented as the mean \pm standard error $(\mathrm{n}=3)$. ${ }^{* *} \mathrm{P}<0.01$, vs. negative control group. LPS, lipopolysaccharide; IL, interleukin

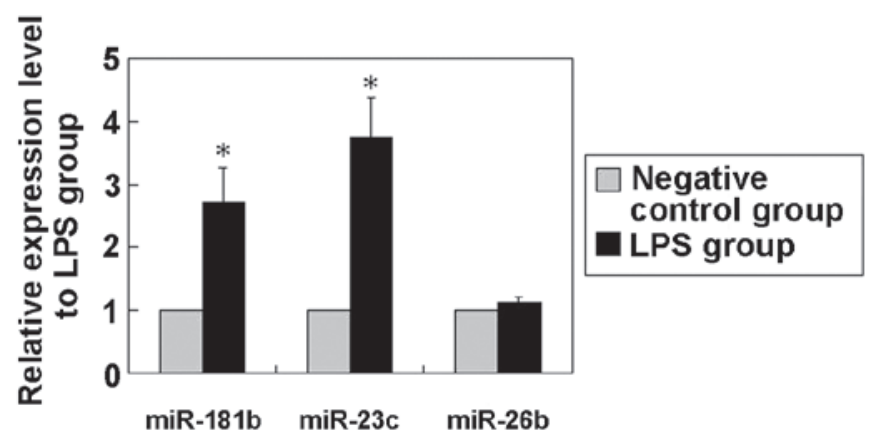

Figure 2. Expression levels of miR-181b, miR-23c and miR-26b in BEAS-2B human bronchial epithelial cells with or without LPS stimulation (LPS and negative control groups, respectively) was assessed using reverse transcription-quantitative polymerase chain reaction. The expression levels of miR-181b and miR-23c appeared significantly increased following LPS stimulation in BEAS-2B cells. The miRNA expression values in the untreated group were set to 1, and the relative amount of the miRNAs in the LPS group was plotted as a logarithmic fold induction. The data are expressed as the mean \pm standard error $(n=3)$. " $P<0.05$, vs. negative control group. LPS, lipopolysaccharide; miR or miRNA, microRNA.

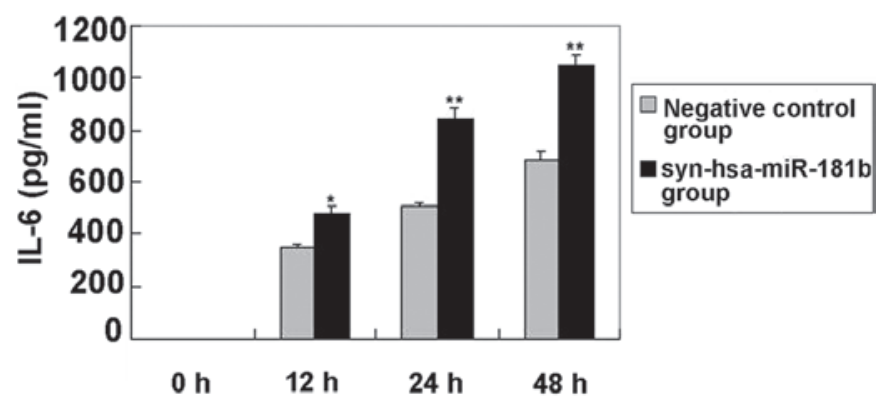

Figure 3. Syn-hsa-miR-181b-induced time-dependent release of IL-6 in BEAS-2B human bronchial epithelial cells. Cells were cultured with the negative control and syn-hsa-miR-181b, for 0,12 and $48 \mathrm{~h}$. Conditioned media were aspirated at each time interval and assayed for cytokine release by ELISA. The data are expressed as $\mathrm{pg} / \mathrm{ml}$ of conditioned media and presented as the mean \pm standard error $(n=3)$. ${ }^{*} \mathrm{P}<0.05$ and ${ }^{* *} \mathrm{P}<0.01$, vs. negative control group. IL, interleukin; miR or miRNA, microRNA.

miR-181b expression level in the BEAS-2B cells was $<50 \%$ of that in the LPS-stimulated BEAS-2B cells (Fig. 2), suggesting that miR-181b expression may be positively correlated with the LPS-induced ALI model. 
Table I. MicroRNA array analysis identified that 41 miRNAs were in response to lipopolysaccharide stimulation in human bronchial epithelial cells.

\begin{tabular}{|c|c|c|c|c|}
\hline No. & Probe_ID & $\begin{array}{l}\text { Sample A signal } \\
\text { (prestimulation) }\end{array}$ & $\begin{array}{l}\text { Sample B signal } \\
\text { (poststimulation) }\end{array}$ & $\begin{array}{c}\log 2 \\
(\text { Sample B/Sample A) }\end{array}$ \\
\hline 1 & hsa-miR-3613-3p & 206.97 & 520.07 & 1.27 \\
\hline 2 & hsa-miR-335 & 338.68 & 853.34 & 1.25 \\
\hline 3 & hsa-miR-26b & 638.32 & $1,490.33$ & 1.20 \\
\hline 4 & hsa-miR-23c & 778.64 & $1,834.46$ & 1.19 \\
\hline 5 & hsa-miR-181b & 380.03 & 821.69 & 1.15 \\
\hline 6 & hsa-miR-1275 & $1,079.12$ & 567.94 & -1.00 \\
\hline 7 & hsa-miR-155 & $1,623.95$ & 812.00 & -0.98 \\
\hline 8 & hsa-miR-4324 & 450.65 & 838.80 & 0.91 \\
\hline 9 & hsa-miR-27a & $1,120.89$ & $2,037.10$ & 0.86 \\
\hline 10 & hsa-miR-15a & 338.01 & 610.37 & 0.86 \\
\hline 11 & hsa-miR-320d & $3,035.04$ & $1,678.92$ & -0.82 \\
\hline 12 & hsa-miR-224 & $1,684.58$ & $2,870.00$ & 0.80 \\
\hline 13 & hsa-miR-320e & $2,374.19$ & $1,410.80$ & -0.75 \\
\hline 14 & hsa-let-7e & $3,773.71$ & $6,116.64$ & 0.70 \\
\hline 15 & hsa-miR-27b & $2,148.34$ & $3,339.14$ & 0.68 \\
\hline 16 & hsa-let-7g & $2,219.58$ & $3,507.05$ & 0.67 \\
\hline 17 & hsa-miR-320a & $4,671.19$ & $3,001.94$ & -0.64 \\
\hline 18 & hsa-miR-320b & $4,521.04$ & $2,934.64$ & -0.62 \\
\hline 19 & hsa-let-7b & $11,003.42$ & $7,216.83$ & -0.62 \\
\hline 20 & hsa-miR-320c & $4,945.14$ & $3,247.34$ & -0.56 \\
\hline 21 & hsa-miR-107 & $1,142.26$ & $1,659.61$ & 0.54 \\
\hline 22 & hsa-miR-17 & 998.00 & $1,441.09$ & 0.53 \\
\hline 23 & hsa-miR-1246 & $5,445.48$ & $3,735.81$ & -0.51 \\
\hline 24 & hsa-miR-181a & 626.31 & 889.46 & 0.51 \\
\hline 25 & hsa-miR-92b & $1,925.05$ & $1,373.15$ & -0.49 \\
\hline 26 & hsa-miR-21 & $15,567.78$ & $21,195.97$ & 0.46 \\
\hline 27 & hsa-miR-103 & $1,464.21$ & $1,991.04$ & 0.44 \\
\hline 28 & hsa-miR-222 & $6,340.95$ & $4,743.61$ & -0.42 \\
\hline 29 & hsa-miR-92a & $4,248.12$ & $3,181.43$ & -0.41 \\
\hline 30 & hsa-miR-25 & $2,094.70$ & $2,733.08$ & 0.38 \\
\hline 31 & hsa-miR-15b & $4,844.80$ & $5,967.15$ & 0.34 \\
\hline 32 & hsa-miR-26a & $5,491.24$ & $6,963.52$ & 0.34 \\
\hline 33 & hsa-miR-20a & $1,251.63$ & $1,569.61$ & 0.33 \\
\hline 34 & hsa-let-7a & $18,911.99$ & $15,386.43$ & -0.30 \\
\hline 35 & hsa-miR-638 & $3,327.89$ & $2,721.15$ & -0.29 \\
\hline 36 & hsa-let-7i & $3,071.09$ & $3,725.29$ & 0.28 \\
\hline 37 & hsa-miR-23b & $12,277.94$ & $15,069.06$ & 0.27 \\
\hline 38 & hsa-miR-3665 & $12,100.79$ & $10,305.79$ & -0.23 \\
\hline 39 & hsa-miR-23a & $12,915.30$ & $14,893.35$ & 0.21 \\
\hline 40 & hsa-miR-16 & $9,758.49$ & $8,615.40$ & -0.18 \\
\hline 41 & hsa-let-7c & $13,839.79$ & $12,196.52$ & -0.17 \\
\hline
\end{tabular}

The microarray contained three probe replicates for each miRNA. Dual-color fluorescence hybridization results of each probe were calculated based on the ratio $\mathrm{Cy} 5 / \mathrm{Cy} 3$. For signal homogeneity, the median signal of each probe was defined as the real signal. The log ratio of each probe was calculated and the median log ratio of three replicated probes was defined as the real ratio. miRNA or miR, microRNA; hsa, Homo sapiens.

Increased levels of IL-6 in BEAS-2B cells following syn-hsa-miR-181b transfection. Following syn-hsa-miR-181b transfection, the levels of IL-6 in the cultured supernatants of the BEAS-2B cells were determined using ELISA. Fig. 3 shows that the IL-6 levels were clearly elevated in the syn-hsa-miR-181b-transfected cells compared with the negative 
A

$\begin{array}{rcccccccccc}\text { Negative Control } & - & + & - & - & - & - & - & - & - & - \\ \text { syn-hsa-miR-181b } & - & - & - & - & - & - & + & + & + & + \\ \text { LPS } & - & - & + & + & + & + & - & - & - & - \\ \text { PDTC }(\mu \mathrm{M}) & - & - & 0 & 50 & 100200 & 0 & 50 & 100 & 200\end{array}$

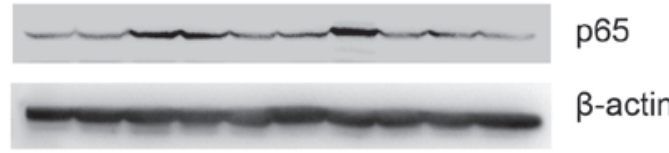

B

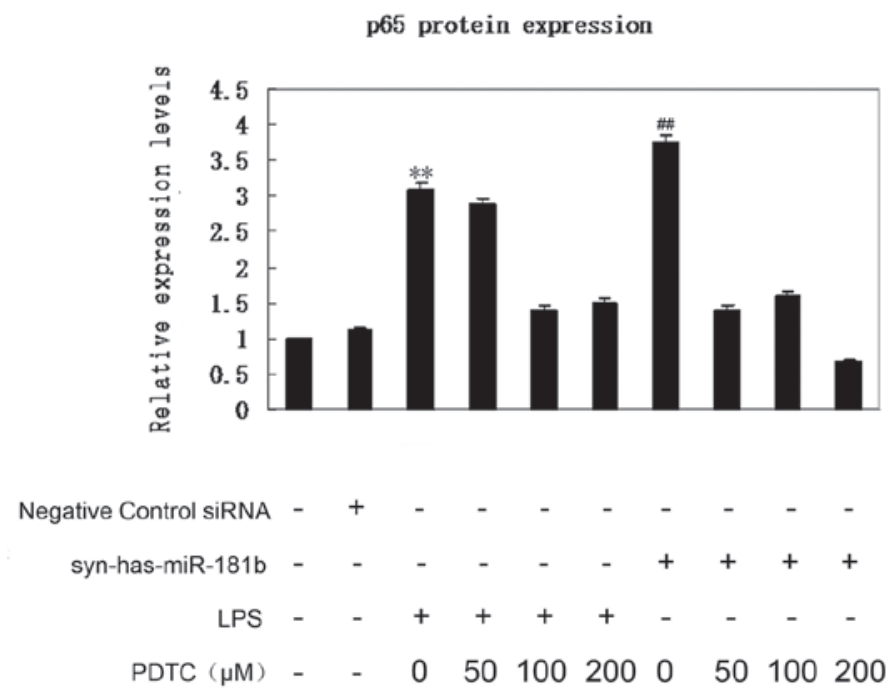

Figure 4. PDTC abrogated upregulation of p65 expression in response to syn-hsa-miR-181b transfection. p65 expression was significantly increased following transfection with syn-has-miR-181b, while the negative control group had little effect on p65 expression. (A) Representative image of western blotting from three repeated experiments, and (B) relative protein expression levels of $\mathrm{p} 65$, as determined using ImageJ software. ${ }^{* *} \mathrm{P}<0.01$ vs. negative control group. PDTC can abrogate the upregulation of $\mathrm{p} 65$ expression. ${ }^{\# \prime} \mathrm{P}<0.01$, vs. $100 \mu \mathrm{M}$ PDTC group. Representative images were acquired from three different experiments. LPS, lipopolysaccharide; PDTC, ammonium pyrrolidinedithiocarbamate.

control levels. The lack of detectable TNF- $\alpha$ was unexpected, since this particular cytokine has been reported to be involved in the regulation of IL-6 and IL-8 (29).

$N F-\kappa B$ inhibitors abrogate upregulation of p65 expression in response to syn-hsa-miR-181b transfection. Increased nuclear p65 protein shows that the NF- $\mathrm{kB}$ signaling pathway is activated. The p65 expression was therefore first examined using western blot analysis (Fig. 4A). According to the data, an elevated expression of p65 was observed in the syn-hsa-miR-181b-transfected BEAS-2B cells, which was comparable with that of the LPS treatment group. By contrast, the negative control had little effect on p65 expression (Fig. 4B). To further confirm the effect of miR-181b on the expression of p65, BEAS-2B cells were treated with PDTC $1.5 \mathrm{~h}$ prior to syn-hsa-miR-181b-transfection. As shown in Fig. 4A, even a low dose $(50 \mu \mathrm{M})$ of PDTC treatment markedly abrogated the upregulation of p65 expression. This inhibition of PDTC on p65 expression was also observed in the LPS-treated cells. These findings demonstrated a critical link between miR-181b and the NF-kB signaling pathway in ALI.

\section{Discussion}

miRNAs have been demonstrated to play a central role in the regulation of the immune system development, proliferation of monocytes and neutrophils, antibody production, differentiation of B- and T-cells, release of inflammatory mediators (30) and certain inflammatory lung diseases. Thus, miRNAs may also contribute to the pathogenesis of ALI/ARDS. miR-181b has been found to be a key player in a positive feedback loop that links inflammation to an epigenetic switch controlling cellular transformation in MCF-10A human mammary epithelial cells (20). Sun et al (31) revealed that miR-181b regulates NF- $\kappa \mathrm{B}$-mediated endothelial cell activation and vascular inflammation in response to proinflammatory stimuli. In addition, the rescue of miR-181b expression may provide a novel target for the treatment of critical diseases, such as diabetes, arthritis, and other chronic inflammatory diseases, as well as for anti-inflammatory treatment (31). In order to identify potential miRNAs involved in ALI, the miRNAs expression profile was analyzed in BEAS-2B cells with or without LPS treatment. Notably, 41 miRNAs displayed significantly differential expression levels (Table I). The results of qPCR revealed a 2-3-fold increase in miR-181b expression in the LPS-treated cells compared with the non-LPS-treated BEAS-2B cells. Transfection based approaches were further utilized in order to establish the promoting role of miR-181b in BEAS-2B cells.

BEAS-2B cells were selected as representative airway epithelial cell lines (32) for the purpose of studying the 
LPS-induced effects in the airway epithelium. BEAS-2B cells mimic the primary bronchial epithelial cells considerably well (33) and have been extensively used to investigate LPS-induced activation of pro-inflammatory cytokines as an in vitro model based on the first steps in the development of sepsis-induced ALI/ARDS (34,35). E. coli LPS treatment was selected due to its use in the majority of endotoxin-induced lung injury models $(36,37)$. Furthermore, LPS is a key pathogen recognition molecule for sepsis (38), inducing apoptosis in lung cells (39).

For the examination of the cellular function of miR-181b, an overexpression approach in cultured BEAS-2B cells was used to detect the levels of TNF- $\alpha$ and IL-6. In the present study, it was demonstrated that the upregulation of miR-181b in BEAS-2B cells can increase the IL-6 expression. Iliopoulos et al (20) reported that, in human mammary epithelial MCF-10A cells, the inhibition of miR-181b expression, which is accomplished by treating cells with antisense RNAs against miR-181b, results in a reduced production of IL-6, a direct NF- $\kappa B$ target gene, and reduced NF- $\kappa B$ activity. BEAS-2B cells are also epithelial cells and therefore the use of anti-miR-181b was not required in the present study. IL-8 was not detected, since the release of inflammation factor IL-8 in response to particulate matter $(\leq 2.5 \mu \mathrm{m})$ and LPS treatment was qualitatively similar to the IL-6 responses, suggesting a common or closely-associated mechanism (40). However, besides the secretion of inflammatory factors, other aspects, such as the anti-apoptosis of lung cells (41) and the promotion of immunocyte transmigration (42), may also be involved in ALI.

$\mathrm{NF}-\mathrm{kB}$, a type of multidirectional nuclear transcriptional regulatory factor, regulates the expression of proteins and genes associated with inflammation, immunization, and growth regulation (43). In the present study, it was found that the overexpression of miR-181b leads to the upregulation of p65 expression, which is a member of the NF- $\mathrm{KB}$ signaling pathway. The present findings indicated that miR-181b acts as a proinflammatory factor through the targeting of the NF- $\mathrm{KB}$ signaling pathway in vitro. This conclusion is supported by the following evidence: First, the present study demonstrated that the upregulation of miR-181b in BEAS-2B cells can increase the expression of IL-6, a direct NF- $\mathrm{kB}$ target gene. In addition, western blot analysis identified that $\mathrm{p} 65$ was upregulated in the BEAS-2B cells following miR-181b overexpression. It was further demonstrated that PDTC abrogated an miR-181b-mediated p65 increase. Compared with the negative control group, p65 expression exhibited an $\sim 3$.7-fold increase following miR-181b overexpression, whereas the inhibition of NF- $\kappa$ B reduced the $\mathrm{p} 65$ expression by $50 \%$ following miR- $181 \mathrm{~b}$ overexpression; however the exact mechanism remains unclear. It has been reported that PDTC potently inhibits the activation and/or interaction of NF- $\mathrm{KB}$ with its upstream regulatory binding sites, thereby preventing NF- $\kappa \mathrm{B}$-mediated transcriptional activation $(44,45)$. Furthermore, PDTC restrains I $\mathrm{B}$ degradation, thus specifically inhibiting NF- $\mathrm{kB}$ activation (46).

The present study revealed that a collection of miRNAs was aberrantly expressed in the LPS-treated BEAS-2B cells, and focused on the effects of miR-181b on inflammation in BEAS-2B cells; however, several other miRNAs, such as miR-23c, were also dynamically regulated in LPS-induced
ALI. Whether these miRNAs are also associated with LPS-induced lung injury remains to be elucidated. The use of bioinformatics to predict specific targets of miR-181b and the use of luciferase assay to show whether these genes are specific targets of miR-181b should be investigated in future studies.

In conclusion, while $>1,000$ human mature miRNA sequences are listed in the miRNA registry (47), only a handful have been characterized as functional regulators of leukocyte or endothelial cell inflammatory responses $(48,49)$. The present study demonstrated that miR-181b is involved in LPS-induced lung injury. Specifically, miR-181b was found to serve as a potent regulator to promote inflammation through the NF- $\kappa \mathrm{B}$ signaling pathway in the BEAS-2B cells. These findings may have important implications in the regulation of the adaptive immune response in ALI. Thus far, there is promising evidence supporting the potential application of miRNAs as novel therapeutic targets, as well as biomarkers for ALI; however, this requires further investigation prior to application in the daily management of ALI. Further studies on the genetic variation associated with miRNAs in real patient populations may help achieve the ultimate goal of providing personalized medical care for inflammatory lung disease. Considering inflammation as a system disorder (50), it would be interesting to examine whether miR-181b is also involved in the inflammation in vivo.

\section{Acknowledgements}

This study was supported by grants from the National Natural Science Foundation of China (no.31201040), Science Technology Department of Zhejiang Province (no. 2012C24005), Health Bureau of Zhejiang Province (nos. 11-CX01 and 2013ZDA002), Zhejiang Provincial Administration of traditional Chinese Medicine (no. 2012-XK-A04) and Natural Science Foundation of Zhejiang Province (no. Y14H010013). The authors would like to thank all the members of the laboratory for helpful discussions and comments on the manuscript.

\section{References}

1. Avecillas JF, Freire AX and Arroliga AC: Clinical epidemiology of acute lung injury and acute respiratory distress syndrome: Incidence, diagnosis and outcomes. Clin Chest Med 27: 549-557, 2006.

2. Ware LB and Matthay MA: The acute respiratory distress syndrome. N Engl J Med 342: 1334-1349, 2000.

3. Crosby LM and Waters CM: Epithelial repair mechanisms in the lung. Am J Physiol Lung Cell Mol Physiol 298: L715-L731, 2010.

4. Papi A and Johnston SL: Rhinovirus infection induces expression of its own receptor intercellular adhesion molecule 1 (ICAM-1) via increased NF-kappaB-mediated transcription. J Biol Chem 274: 9707-9720, 1999.

5. Hoare GS, Chester AH, Yacoub MH and Marczin N: Regulation of NF-kappaB and ICAM-1 expression in human airway epithelial cells. Int J Mol Med 9: 35-44, 2002.

6. Li Z, Zhang de K, Yi WQ, Ouyang Q, Chen YQ and Gan HT: NF-kappaB p65 antisense oligonucleotides may serve as a novel molecular approach for the treatment of patients with ulcerative colitis. Arch Med Res 39: 729-734, 2008.

7. Bartel DP: MicroRNAs: Target recognition and regulatory functions. Cell 136: 215-233, 2009.

8. Guo H, Ingolia NT, Weissman JS and Bartel DP: Mammalian microRNAs predominantly act to decrease target mRNA levels. Nature 466: 835-840, 2010.

9. Bartel DP: MicroRNAs: Genomics, biogenesis, mechanism and function. Cell 116: 281-297, 2004. 
10. Latronico MV and Condorelli G: MicroRNAs and cardiac pathology. Nat Rev Cardiol 6: 419-429, 2009.

11. Port JD and Sucharov C: Role of microRNAs in cardiovascular disease: Therapeutic challenges and potentials. J Cardiovasc Pharmacol 56: 444-453, 2010.

12. Buechner J, Henriksen JR, Haug BH, Tømte E, Flaegstad T and Einvik C: Inhibition of mir-21, which is upregulated during MYCN knockdown-mediated differentiation, does not prevent differentiation of neuroblastoma cells. Differentiation 81: 25-34, 2011

13. Li X, Zhang Y, Shi Y, Dong G, Liang J, Han Y, Wang X, Zhao Q, Ding J, Wu K, et al: MicroRNA-107, an oncogene microRNA that regulates tumour invasion and metastasis by targeting DICER 1 in gastric cancer. J Cell Mol Med 15: 1887-1895, 2011.

14. O'Connell RM, Rao DS, Chaudhuri AA and Baltimore D: Physiological and pathological roles for microRNAs in the immune system. Nat Rev Immunol 10: 111-122, 2010.

15. Oglesby IK, McElvaney NG and Greene CM: MicroRNAs in inflammatory lung disease-master regulators or target practice? Respir Res 11: 148, 2010.

16. Roggli E, Britan A, Gattesco S, Lin-Marq N, Abderrahmani A, Meda P and Regazzi R: Involvement of microRNAs in the cytotoxic effects exerted by proinflammatory cytokines on pancreatic beta-cells. Diabetes 59: 978-986, 2010.

17. Angulo M, Lecuona E and Sznajder JI: Role of MicroRNAs in lung disease. Arch Bronconeumol 48: 325-330,2012 (In English, Spanish).

18. Cai ZG, Zhang SM, Zhang Y, Zhou YY, Wu HB and Xu XP MicroRNAs are dynamically regulated and play an important role in LPS-induced lung injury. Can J Physiol Pharmacol 90: 37-43, 2012.

19. Xie T, Liang J, Liu N, Wang Q, Li Y, Noble PW and Jiang D: MicroRNA-127 inhibits lung inflammation by targeting IgG Fc $\gamma$ receptor I. J Immunol 188: 2437-2444, 2012.

20. Iliopoulos D, Jaeger SA, Hirsch HA, Bulyk ML and Struhl K: STAT3 activation of miR-21 and miR-181b-1 via PTEN and CYLD are part of the epigenetic switch linking inflammation to cancer. Mol Cell 39: 493-506, 2010.

21. Wang YZ, Mao GX, Lv YD, Huang QD and Wang GF MicroRNA-181b stimulates inflammation via the NF-kappa B signaling pathway in vitro. J Am Geriatr Soc 62: S394-S394, 2014

22. Schulz C, Farkas L, Wolf K, Kratzel K, Eissner G and Pfeifer M Differences in LPS-induced activation of bronchial epithelial cells (BEAS-2B) and type II-like pneumocytes (A-549). Scand J Immunol 56: 294-302, 2002.

23. Pencheva N, Tran H, Buss C, Huh D, Dorbnjak M, Busam K and Tavazoie SF:Concergent multi-miRNA targeting of ApoE drives LRP1/LRP8-dependent melanoma metastasis and angiogenesis. Cell 151: 1068-1082, 2012.

24. Ma Y, Zhang P, Wang F, Zhang H, Yang J, Peng J, Liu W and Qin H: miR-150 as a potential biomarker associated with prognosis and therapeutic outcome in colorectal cancer. Gut 61: $1447-1453,2012$

25. Elder ACP, Gelein R, Finkelstein JN, Cox C and Oberdorster G: Endotoxin priming affects the lung response to ultrafine particles and ozone in young and old rats. Inhalation Toxicology 12 (Suppl 1): 85-98, 2000.

26. Meduri GU, Headley S, Kohler G, Stentz F, Tolley E, Umberger R and Leeper K: Persistent elevation of inflammatory cytokines predicts a poor outcome in ARDS. Plasma IL-1 beta and IL-6 levels are consistent and efficient predictors of outcome over time. Chest 107: 1062-1073, 1995.

27. Dave RS and Khalili K: Morphine treatment of human monocyte-derived macrophages induces differential miRNA and protein expression: Impact on inflammation and oxidative stress in the central nervous system. J Cell Biochem 110: 834-845, 2010.

28. Ma X, Becker Buscaglia LE, Barker JR and Li Y: MicroRNAs in NF-kappaB signaling. J Mol Cell Biol 3: 159-166, 2011.

29. Nelson S and Martin TR: Cytokines in Pulmonary Disease: Infection and Inflammation (Lung Biology in Health and Disease). Martin T (ed). Volume 141. 1st edition. Marcel Dekker, New York, NY, 2000

30. Pedersen I and David M: MicroRNAs in the immune response. Cytokine 43: 391-394, 2008.

31. Sun X, Icli B, Wara AK, Belkin N, He S, Kobzik L, Hunninghake GM, Vera MP, MICU Registry, Blackwell TS, et al: MicroRNA-181b regulates NF- $\kappa$ B-mediated vascular inflammation. J Clin Invest 122: 1973-1990, 2012.
32. Koyama S, Sato E, Nomura H, Kubo K, Miura M, Yamashita T, Nagai S and Izumi T: The potential of various lipopolysaccharides to release monocyte chemotactic activity from lung epithelial cells and fibroblasts. Eur Respir J 14: 545-552, 1999.

33. Reddel RR, Ke Y, Gerwin BI, McMenamin MG, Lechner JF, Su RT, Brash DE, Park JB, Rhim JS and Harris CC: Transformation of human bronchial epithelial cells by infection with SV40 or adenovirus-12 SV40 hybrid virus, or transfection via strontium phosphate coprecipitation with a plasmid containing SV40 early region genes. Cancer Res 48: 1904-1909, 1988

34. Boots AW, Gerloff K, Bartholomé R, van Berlo D, Ledermann K, Haenen GR, Bast A, van Schooten FJ, Albrecht C and Schins RP: Neutrophils augment LPS-mediated pro-inflammatory signaling in human lung epithelial cells. Biochim Biophys Acta 1823: $1151-1162,2012$.

35. Yeh CH, Cho W, So EC, Chu CC, Lin MC, Wang JJ and Hsing CH: Propofol inhibits lipopolysaccharide-induced lung epithelial cell injury by reducing hypoxia-inducible factor-1alpha expression. Br J Anaesth 106: 590-599, 2011

36. Fortis S, Spieth PM, Lu WY, Parotto M, Haitsma JJ, Slutsky AS, Zhong N, Mazer CD and Zhang H: Effects of anesthetic regimes on inflammatory responses in a rat model of acute lung injury. Intensive Care Med 38: 1548-1555, 2012.

37. Mittal N and Sanyal SN: In vivo effect of surfactant on inflammatory cytokines during endotoxin-induced lung injury in rodents. J Immunotoxicol 8: 274-283, 2011.

38. Cheng DS, Han W, Chen SM, Sherrill TP, Chont M, Park GY, Sheller JR, Polosukhin VV, Christman JW, Yull FE, et al: Airway epithelium controls lung inflammation and injury through the NF-kappa B pathway. J Immunol 178: 6504-6513, 2007.

39. Tang PS, Mura M, Seth R and Liu M: Acute lung injury and cell death: How many ways can cells die? Am J Physiol Lung Cell Mol Physiol 294: L632-L641, 2008.

40. Veranth JM, Reilly CA, Veranth MM, Moss TA, Langelier CR, Lanza DL and Yost GS: Inflammatory cytokines and cell death in BEAS-2B lung cells treated with soil dust, lipopolysaccharide and surface-modified particles. Toxicol Sci 82: 88-96, 2004.

41. Stern JB, Jaffré S, Dehoux M and Crestani B: Keratinocyte growth factor and Hepatocyte growth factor: Their roles in alveolar epithelial repair. Rev Mal Respir 20: 896-903, 2003.

42. Hoke TS, Douglas IS, Klein CL, He Z, Fang W, Thurman JM, Tao Y, Dursun B, Voelkel NF, Edelstein CL, et al: Acute renal failure after bilateral nephrectomy is associated with cytokine-mediated pulmonary injury. J Am Soc Nephrol 18: 155-164, 2007.

43. Hayden MS and Ghosh S: Shared principles in NF-kappaB signaling. 132: 344-362, 2008.

44. Kawai M, Nishikomori R, Jung EY, Tai G, Yamanaka C, Mayumi M and Heike T: Pyrrolidine dithiocarbamate inhibits intercellular adhesion molecule-1 biosynthesis induced by cytokines in human fibroblasts. J Immunol 154: 2333-2341, 1995.

45. Schreck R, Meier B, Männel DN, Dröge W and Baeuerle PA Dithiocarbamates as potent inhibitors of nuclear factor kappa B activation in intact cells. J Exp Med 175: 1181-1194, 1992.

46. Zhang M, Zhou SH, Li XP, Shen XQ, Fang ZF, Liu QM, Qiu SF and Zhao SP: Atorvastatin downregulates BMP-2 expression induced by oxidized low-density lipoprotein in human umbilical vein endothelial cells. Circ J 72: 807-812, 2008

47. Griffiths-Jones S: The microRNA Registry. Nucleic Acids Res 32: D109-D111, 2004.

48. Fang Y, Shi C, Manduchi E, Civelek M and Davies PF: MicroRNA-10a regulation of proinflammatory phenotype in athero-susceptible endothelium in vivo and in vitro. Proc Natl Acad Sci USA 107: 13450-13455, 2010.

49. Suárez Y, Wang C, Manes TD and Pober JS: Cutting edge: TNF-induced microRNAs regulate TNF-induced expression of E-selectin and intercellular adhesion molecule-1 on human endothelial cells: Feedback control of inflammation. J Immunol 184: 21-25, 2010.

50. Pugin J, Ricou B, Steinberg KP, Suter PM and Martin TR: Proinflammatory activity in bronchoalveolar lavage fluids from patients with ARDS, a prominent role for interleukin-1. Am J Respir Crit Care Med 153: 1850-1856, 1996. 